\title{
Sea Sickness
}

National Cancer Institute

\section{Source}

National Cancer Institute. Sea Sickness. NCI Thesaurus. Code C35011.

A sensation of discomfort associated with travel over water, which may include nausea, vomiting, dizziness, or sweating. 